\title{
Comment on Memisoglu et al.: Does the technique of lateral cross-wiring (Dorgan's technique) reduce iatrogenic ulnar nerve injury?
}

\author{
A. R. Nataraj • T. Sreenivas $\cdot$ J. Naik
}

Received: 14 August 2010 /Accepted: 29 September 2010 /Published online: 22 October 2010

(C) Springer-Verlag 2010

\section{Dear Editor,}

We congratulate Kaya Memisoglu et al. for their excellent paper entiteled "Does the technique of lateral cross-wiring (Dorgan's technique) reduce iatrogenic ulnar nerve injury?" [1]. The preferred method of fixation of supracondylar fractures in humerus is still controversial. In this article we noticed that in the X-rays in figures 1 and 2, only anteroposterior views are shown, with no lateral views. Also in figure 1 the lateral pin is protruding significantly into the soft tissues medially. There may be risk of ulnar nerve injury by the pin inserted from the lateral epicondyle protruding medially. There is also risk of late migration of K-wires passed from the lateral humerus beyond the medial epicondyle with risk of injuring the ulnar nerve in these cases. In this study the operations are done by different surgeons, so that the incidence of ulnar nerve injury in the crossed K-wire fixation group may be attributed to the surgery performed by a less experienced surgeon.

The study also did not mention the position of the elbow while passing the medial pins. Various methods of

A. R. Nataraj · T. Sreenivas $(\bowtie)$

Department of Orthopedics, Jawaharlal Institute of Post Graduate

Medical Education and Research (JIPMER),

Dhanvantrinagar,

Puducherry 605006, India

e-mail: sreenivas6@rediffmail.com

A. R. Nataraj

e-mail: natadoc@rediffmail.com

J. Naik

Department of Anaesthesia, Indira Gandhi Government General

Hospital and Post Graduate Institute (IGGGH\&PGI),

Puducherry, India

e-mail: naikpuja8@gmail.com avoiding ulnar nerve injury have been mentioned in literature, such as locating the ulnar nerve with a nerve stimulator suggested by Micheal and Stanislas [2]. Making a small $1.5-\mathrm{cm}$ incision over the medial epicondyle for placement of the medial pin has also been proposed as a way to locate and protect the ulnar nerve. This technique works well and may avert the problem of iatrogenic ulnar nerve injury when crossed pinning is required for very unstable fractures. Furthermore, placing the lateral pin first with the elbow hyperflexed and then placing the medial pin with the elbow in only 90 degrees of flexion lessens this risk.

In a biomechanical analysis of lateral pinning versus crossed pinning, Lee et al. [3] found that divergence of two lateral pins was superior to a parallel configuration. They found crossed pins provided significantly more strength in axial rotation. Onwuanyi and Nwobi [4], in a clinical series, also concluded that there was greater stability or ability to maintain reduction with the crossed pinning technique. Solak and Aydin, however, found no difference in complication rates with two lateral pins versus crossed pins [5]. In addition there is a theoretical possibility of injuring the radial nerve during the insertion of the pin from the lateral humerus. Thus, we maintain that if properly done the medio-lateral cross K-wire fixation method provides good stability with less chance of nerve injury.

\section{References}

1. Memisoglu K, Cevdet Kesemenli C, Atmaca H (2010) Does the technique of lateral cross-wiring (Dorgan's technique) reduce iatrogenic ulnar nerve injury? Int Orthop. July 20. [Epub ahead of print] 
2. Michael SP, Stanislas MJ (1996) Localization of the ulnar nerve during percutaneous wiring of supracondylar fractures in children. Injury 27(5):301-302

3. Lee SS, Mahar AT, Miesen D, Newton PO (2002) Displaced pediatric supracondylar humerus fractures: biomechanical analysis of percutaneous pinning techniques. J Pediatr Orthop 22:440-443
4. Onwuanyi ON, Nwobi DG (1998) Evaluation of the stability of pin configuration in K-wire fixation of displaced supracondylar fractures in children. Int Surg 83(3):271-274

5. Solak S, Aydin E (2003) Comparison of two percutaneous pinning methods for the treatment of the pediatric type III supracondylar humerus fractures. J Pediatr Orthop B 12(5):346-349 